\title{
PENINGKATAN PROFESIONALISME GURU DAN TUTOR PAUD MELALUI PELATIHAN PEMBUATAN PERANGKAT PEMBELAJARAN DALAM UPAYA PENERAPAN KURIKULUM PAUD TAHUN 2013 DI DESA CIBITUNG TENGAH KECAMATAN TENJOLAYA KABUPATEN BOGOR PROVINSI JAWA BARAT
}

\author{
Yenina Akmal, Hikmah, Santi Susanti Ika Subekti, Agus Kurniawan, Ichtineza Halida \\ Hardono \\ Pendidikan Anak Usia Dini, Universitas Negeri Jakarta \\ yenina.akmal@yahoo.com
}

\begin{abstract}
The problem that arises in Cibitung Tengah Village is the lack of educators working in this village. Most of these educators were not coming from early childhood education background. The limited access to the information had caused ECE teachers and tutors to not understand the 2013 ECE curriculum. Limited knowledge about the 2013 ECE curriculum had an impact on the lack of knowledge of teachers and tutors in making learning devices. Learning devices consist of RPPH, media, evaluation and learning assessment and must be made by the educators before conducting and starting learning activities. Learning devices were an important component in organizing learning activities. This aimed to improve the quality of education which is the goal of this nation. The solution was training and awareness and dissemination of THE 2013 ECE curriculum. In addition, improving the quality of ECE teachers and tutors in making learning devices can be improved. The target to be achieved through the Community Service Activities was an increase in the knowledge of ECE teachers and tutors regarding the 2013 ECE curriculum and also how to make the right learning devices for early childhood learning activities.
\end{abstract}

Keywords: Early Childhood Education, 2013 Curriculum, Learning Devices

\begin{abstract}
Abstrak
Permasalahan yang muncul di Desa Cibitung Tengah ini adalah minimnya tenaga pendidik yang bertugas di Desa ini. Sebagian besar tenaga pendidik ini bukanlah berlatar belakang tentang pendidikan anak usia dini. Keterbatasan akses informasi menyebabkan guru dan tutor PAUD belum memahami mengenai kurikulum PAUD tahun 2013. Keterbatasan pengetahuan mengenai kurikulum PAUD 2013 berdampak pada minimnya pengetahuan guru dan tutor dalam membuat perangkat pembelajaran. Perangkat pembelajaran terdiri dari RPPH, media, evaluasi dan asesmen pembelajaran harus dibuat oleh tenaga pendidik sebelum melakukan dan memulai kegiatan pembelajaran. Perangkat pembelajaran adalah komponen penting dalam menyelenggarakan kegiatan pembelajaran. Hal ini bertujuan untuk meningkatkan kualitas pendidikan yang merupakan cita-cita bangsa ini. Solusinya adalah pelatihan dan penyadaran serta sosialisasi mengenai kurikulum PAUD tahun 2013. Selain itu, peningkatan kualitas guru dan tutor PAUD dalam membuat perangkat pembelajaran dapat ditingkatkan. Target yang ingin dicapai melalui Kegiatan Pengabdian kepada Masyarakat ini adalah adanya peningkatan pengetahuan guru dan tutor PAUD mengenai kurikulum PAUD tahun 2013 dan juga cara pembuatan perangkat pembelajaran yang tepat untuk kegiatan pembelajaran anak usia dini.
\end{abstract}

Kata Kunci: Pendidikan Anak Usia Dini, Kurikulum 2013, Perangkat Pembelajaran 
DOI: https://doi.org/10.21009/sarwahita.152.01

P-ISSN: 0216-7484

E-ISSN: 2597-8926

\section{PENDAHULUAN}

Meningkatkan Kualitas Sumber Daya Manusia dapat dilakukan dengan berbagai cara, salah satunya dengan meningkatkan kualitas Pendidikan. Upaya untuk meningkatkan kualitas Sumber Daya Manusia harus dilakukan secara adil dan merata. Hal ini didasarkan pada Undang-Undang Dasar 1945 pasal 31 ayat 1 yang berbunyi 'setiap warga Negara memiliki hak untuk mendapatkan pendidikan'. Pada jenjang pendidikan di bawah Sekolah Dasar, Pemerintah masih kurang memperhatikan. Padahal sejatinya anakanak usia dini berada pada periode emas, karena merupaka masa terpenting manusia untuk mengembangkan seluruh aspek perkembangan (aspek kognitif, sosial emosional, moral - agama, bahasa, motorik, seni: kurikulum 2013). Proses perkembangan pada masa ini harus melalui tahapan demi tahapan yang dibantu oleh orang dewasa, baik orang tua di rumah (Amini 2015) maupun tutor PAUD di lembaga PAUD (Gordon et al 2014).

Namun semua itu tidaklah terlepas dari sumber daya manusia para pendidik yang berada di Lembaga Pendidikan Anak Usia Dini tersebut, karena sumber daya manusia adalah faktor sentral dalam suatu lembaga atau organisasi. Ciri guru / tutor PAUD yang profesional adalah guru yang memiliki kualifikasi akademik (Permen 137 Tahun 2014) serta memiliki 4 kompetensi profesi yang meliputi kompetensi pedagogik (Mirzagitova et al 2015; Barret et al 2013), kompetensi kepribadian, kompetensi profesional dan kompetensi sosial (Winkel 2004).

Kurangnya Pendidikan dan Pengetahuan yang dimiliki para Tutor PAUD tersebut terjadi di banyak wilayah di Indonesia (U.S 2012), salah satu wilayah yang akses pendidikan untuk anak usia dini masih kurang, yaitu di Desa Cibitung Tengah, Kecamatan Tenjolaya, Kabupaten Bogor Propinsi Jawa Barat). Penduduk di Desa Cibitung Tengah berjumlah 10.644 jiwa dengan pembagian 4.971 penduduk laki-laki dan 5.673 penduduk perempuan. Berdasarkan kelompok usia, jumlah penduduk di Desa Cibitung Tengah terlihat pada tabel 1 .

Tabel 1. Jumlah Penduduk Desa Cibitung Tengah Berdasarkan Kelompok Usia dan Jenis Kelamin

\begin{tabular}{|c|c|c|c|}
\hline \multirow[t]{2}{*}{ Kelompok Umur } & \multicolumn{2}{|c|}{ Jumlah Jiwa } & \multirow[t]{2}{*}{ Jumlah } \\
\hline & Laki-laki & Perempuan & \\
\hline $0-4$ & 454 & 434 & 888 \\
\hline $5-9$ & 405 & 509 & 914 \\
\hline 10-14 & 407 & 476 & 883 \\
\hline $15-19$ & 384 & 478 & 862 \\
\hline 20-24 & 549 & 469 & 1018 \\
\hline 25-29 & 478 & 491 & 969 \\
\hline 30-34 & 409 & 538 & 947 \\
\hline 35-39 & 343 & 451 & 794 \\
\hline
\end{tabular}


DOI: https://doi.org/10.21009/sarwahita.152.01

P-ISSN: 0216-7484

E-ISSN: 2597-8926

\begin{tabular}{cccc}
\hline $\mathbf{4 0 - 4 4}$ & 342 & 362 & 704 \\
\hline $\mathbf{4 5 - 4 9}$ & 334 & 391 & 725 \\
\hline $\mathbf{5 0 - 5 4}$ & 263 & 381 & 644 \\
\hline $\mathbf{5 5 - 5 9}$ & 229 & 362 & 591 \\
\hline $\mathbf{6 0 - 6 4}$ & 117 & 186 & 303 \\
\hline $\mathbf{6 5 - 6 9}$ & 94 & 110 & 204 \\
\hline $\mathbf{7 0}-$ keatas & 163 & 35 & 198 \\
\hline
\end{tabular}

Sebagian besar, mata pencaharian penduduk di Desa ini adalah sebagai buruh industri sebanyak 1.534 orang. Sementara yang berprofesi sebagai petani sebanyak 170 orang, pemilik tanah/sawah 140 orang, petani penggarap 137 orang dan buruh tani sebanyak 526 orang. Beberapa mata pencaharian lain yaitu pengusaha kecil dan menengah sebanyak 16 orang, buruh bangunan sebanyak 531 orang, pedagang 344 orang, pengemudi 179 orang, PNS 192 orang, TNI/Polri 1 orang, dan pensiunan TNI/Polri 124 orang.

Visi Desa Cibitung Tengah yaitu MANIS yang merupakan akronim dari Maju, Mandiri, Sejahtera berdasarkan Iman dan Taqwa. Salah satu kondisi yang diharapkan berdasarkan visi tersebut adalah Meningkatnya pendidikan formal secara umum, Meningkatnya penguasaan ilmu pengetahuan dan teknologi, Terwujudnya pembangunan infrasturktur yang menunjang perekonomian desa, Meningkatnya pelayanan publik. Melihat visi tersebut, bahwa aspek pendidikan di Desa Cibitung Tengah berfokus kepada pendidikan formal. Sementara pendidikan non formal belum menjadi fokus pendidikan di desa ini tapi sudah menjadi program proyek yang telah direncanakan. Hal ini terlihat dengan jumlah lembaga anak usia dini yang berjumlah 8 lembaga, terdiri dari 4 lembaga PAUD dan 4 lembaga TK/RA. Jumlah lembaga untuk anak usia dini dirasa sangat kurang jika dilihat dari jumlah anak usia dini yang ada di Desa ini.

Minimnya jumlah lembaga PAUD di desa ini, membuat sekitar 832 orang belum terfasilitasi pendidikan. Banyak faktor yang mempengaruhi, beberapa diantaranya dikarenakan anggapan orang tua bahwa pendidikan bukan menjadi prioritas utama. Selain itu, kondisi lembaga PAUD yang belum dilengkapi sarana dan prasarana yang memadai sehingga membuat guru dan tutor PAUD tidak maksimal dalam memberikan pembelajaran. Jumlah guru dan tutor PAUD yang tidak sebanding dengan jumlah peserta didik juga menjadi masalah di desa ini. Sebagian besar guru dan tutor PAUD berpendidikan rendah sehingga pengetahuan mereka kesulitan dalam menciptakan kegiatan pembelajaran yang tepat untuk anak usia dini.

Dalam menciptakan kegiatan pembelajaran untuk anak usia dini, seorang guru harus mempersiapkan beberapa perangkat pembelajaran, diantaranya RPPH, media dan metode pembelajaran, evaluasi dan asesmen pembelajaran. Menurut Riyanto (2017), 
DOI: https://doi.org/10.21009/sarwahita.152.01

P-ISSN: 0216-7484

E-ISSN: 2597-8926

perangkat pembelajaran berfungsi sebagai rambu - rambu bagi guru untuk melaksanakan pembelajaran di kelas. Persiapan perangkat pembelajaran harus dibuat dan dipikirkan oleh guru dan tutor PAUD sebelum memberikan kegiatan pembelajaran untuk peserta didik agar tujuan pembelajaran yang diaharapkan akan tercapai. Bisa dibayangkan jika guru tidak memiliki pengetahuan dan keterampilan dalam membuat perangkat pembelajaran, dapat dipastikan kualitas pendidikan di daerah tersebut tergolong rendah.

Melihat permasalahan yang terdapat di Desa Cibitung Tengah Kecamatan Tenjolaya Kabupaten Bogor Propinsi Jawa Barat yang sudah di uraikan sebelumnya, salah satu solusi yang ditawarkan untuk menyelesaikan permasalahan tersebut adalah melakukan kegiatan edukasi dan pelatihan dalam rangka meningkatkan pengetahuan dan keterampilan guru dan tutor PAUD untuk membuat perencanaan pembelajaraan. Selain untuk meningkatkan pengetahuan dan keterampilan guru dan tutor PAUD, kegiatan ini dilakukan sebagai upaya sosialisasi kurikulum PAUD tahun 2013.

\section{METODE PELAKSANAAN}

Pengabdian ini diberikan kepada Tutor PAUD perwakilan dari beberapa lokasi, yaitu TK Al - Ghozali, TK Nurul Anwar, RA Arrahman, PAUD Mutiara Bunda, PAUD Nurul Huda, PAUD As Shidiq, PAUD As - Syifa, dan TKA/TPA Al - Hikmah. Adapun kolaborator dalam pengabdian ini yaitu Lurah Desa Cibitung tengah dan ketua HIMPAUDI di desa tersebut.

Pendampingan dilakukan bersama dengan kolaborator mulai dari awal yakni pada waktu observasi, tindakan intervensi dalam bentuk kegiatan 1, 2, 3, 4 hingga 5 kali pertemuan.

Agar tujuan dari program pengabdian kepada masyarakat di Desa Cibitung Tengah Kecamatan Tenjolaya Kabupaten Bogor Propinsi Jawa Barat ini tercapai, maka metode yang digunakan dalam kegiatan ini adalah dengan cara pelatihan. Dipilihnya metode pelatihan diharapkan setiap guru dan tutor PAUD dapat menghasilkan perangkat pembelajaran berupa RPPH, Media dan Metode pembelajaran, Evaluasi dan Asesmen yang tepat untuk pendidikan anak usia dini di lembaga masing-masing.

Teknik yang digunakan dalam penyampaian materi di kegiatan pengabdian kepada masyarakat ini ada 5 teknik, yaitu 1) Teknik Ceramah, 2) Tanya Jawab, 3) Demonstrasi, 4) Diskusi Kelompok (Purwanti 2017), 5) Praktek Langsung. Teknik Ceramah dilakukan saat penyampaian kurikulum PAUD tahun 2013. Hal ini diharapkan menambah pemahaman guru-guru dan tutor-tutor PAUD tentang kurikulum PAUD tahun 2013. Teknik tanya jawab dilakukan ketika sudah selesai penyampaian materi mengenai kurikulum PAUD tahun 2013. Teknik ini membuka kesempatan guru dan tutor untuk bertanya mengenai kendala dan kebingungan dalam impelementasi kurikulum PAUD tahun 2013 di lembaga masing-masing. Selain itu, untuk tim pengabdi, teknik ini dapat melihat bagaimana cara pandang dan kebiasaan 
DOI: https://doi.org/10.21009/sarwahita.152.01

P-ISSN: 0216-7484

E-ISSN: 2597-8926

guru dan tutor dalam pembuatan perangkat pembelajaran untuk anak usia dini.

Demonstrasi atau unjuk kerja adalah tim pengabdi memberikan contoh pembuatan RPPH dan menjabarkan konten apa saja yang terdapat dalam RPPH. Menunjukkan dan memutarkan video tentang metode dan pembuatan media yang dapat dibuat dengan memanfaatkan barang-barang yang terdapat disekitar lingkungan, dan juga membuat asesmen dan evaluasi yang tepat sesuai dengan kebutuhan yang ada di lembaga masing-masing. Melalui teknik demonstrasi atau unjuk kerja ini, diharapkan guru dan tutor PAUD lebih paham dalam pembuatan perangkat pembelajaran. Teknik Demonstrasi sendiri merupakan teknik yang membuat seseorang terlibat langsung dengan objek yang digunakan saat melakukan suatu kegiatan (Anjaswari et al. 2017).

Diskusi kelompok bertujuan untuk menyamakan sudut pandang guru dan tutor dalam pembuatan perangkat pembelajaran. Teknik ini untuk mengetahui sejauh mana pemahaman guru dalam pembuatan perangkat pembelajaran di lembaga masingmasing. Selain itu, teknik ini dapat mengetahui guru atau tutor PAUD yang masih bingung dalam pembuatan RPPH sehingga guru dan tutor PAUD lain dapat memberi penjelasan terhadap guru atau tutor tersebut. Hal ini dianggap efektif karena yang menjelaskan adalah sesama mereka dalam bentuk diskusi kelompok. Teknik yang tidak kalah penting adalah prakatek langsung. Teknik ini diharapkan guru dan tutor merasakan langsung membuat perangkat pembelajaran mulai dari RPPH, media, metode, evaluasi dan asesmen pembelajaran sesuai dengan yang sudah dijelaskan pada teknik sebelumnya. Dengan praktek langsung dalam membuat perangkat pembelajaran, diharapkan guru dan tutor PAUD akan lebih paham mengenai pembuatan perangkat pembelajaran sebelum melakukan kegiatan pembelajaran, dan semoga pengetahuan ini dapat dibawa di lembaga masing-masing setelah program pengabdian ini selesai.

\section{HASIL DAN PEMBAHASAN}

Kegiatan Pengabdian kepada Masyarakat (PkM) dengan judul Peningkatan Profesionalisme Guru dan Tutor PAUD Melalui Pembuatan Perangkat Pembelajaran dalam Upaya Penerapan Kurikulum PAUD tahun 2013 di Desa Cibitung Tengah Kecamatan Tenjolaya Kabupaten Bogor Jawa Barat yang bekerja sama dengan Lurah Desa Cibitung Tengah dan Ketua HIMPAUDI di desa tersebut dilakukan sebanyak 3 kali pertemuan. Pada pertemuan pertama pemberian materi mengenai Pengembangan Kurikulum PAUD Tahun 2013. 


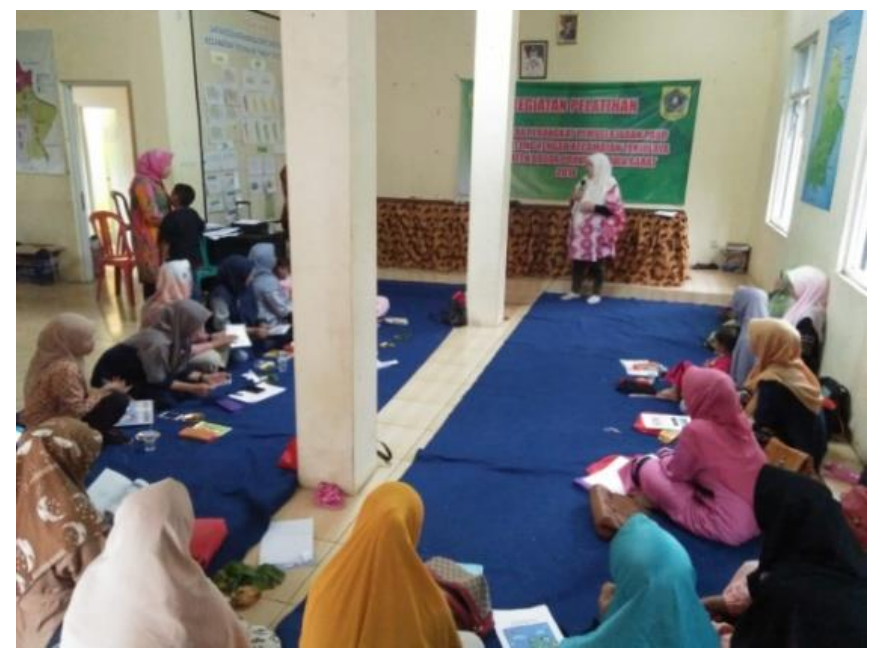

Gambar 1. Kegiatan Pemberian Materi

Pada materi ini sebagian besar mereka belum mengenal kurikulum PAUD 2013. Pembelajaran yang diterapkan di lembaga masing-masing juga masih klasikal. Dengan adanya materi ini, menambah pengetahuan para guru dan tutor PAUD mengenai kurikulum terbaru jenjang PAUD tahun 2013.

Materi berikutnya yaitu Pengenalan Konsep PAUD. Pada materi ini menjelaskan tentang siapa, mengapa dan bagaimana Anak Usia Dini. Pentingnya Pendidikan Anak Usia Dini serta gaya belajar Anak Usia Dini juga dibahas di dalamnya. Materi ini diberikan dengan tujuan para guru dan tutor PAUD dapat mengenal hakikat dari Anak Usia Dini sehingga dapat menyikapi bahwa Anak Usia Dini itu adalah manusia yang unik. Materi selanjutnya yaitu mengenai Pembuatan Perangkat Pembelajaran PAUD Berbasis K-13. Pada penyampaian materi ini mengacu pada kebutuhan dan yang sudah mereka lakukan di lembaga masing-masing. Materi ini meliputi manfaat perangkat pembelajaran, alur pembuatan RPPH, contoh webbing tema, contoh RKH, RKM, semester hingga tahunan. Pada pembuatan Tema, Tema yang disarankan oleh Tim Pengabdian Masyarakat yaitu tema-tema yang dekat dengan anak dengan rentang waktu 1-2 bulan. Diharapkan dengan rentang waktu yang cukup lama membuat anak lebih mengerti dengan tema tersebut dan dapat menguasai materi dengan baik. Hal ini juga meringankan tugas guru dalam mendisplay ruangan kelas sesuai dengan tema yang berlangsung. 


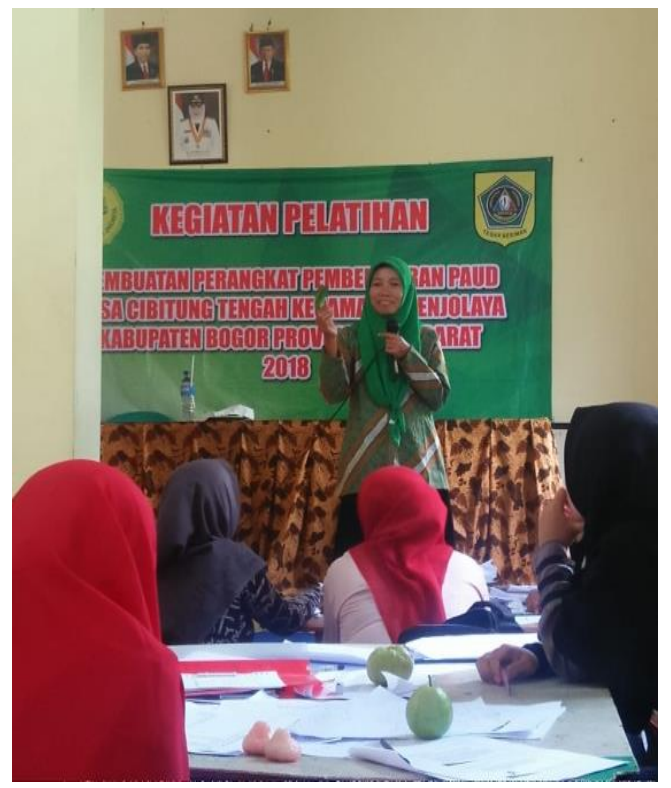

Gambar 2. Tutor PAUD mempresentasikan Tema yang Dipilih

Pada setiap pemberian materi dilakukan sesi Tanya Jawab agar hal hal yang masih belum dimengerti oleh Tutor PAUD menjadi lebih jelas. Setelah itu dilanjutkan dengan kegiatan workshop mengembangkan tema yang telah diberikan sebelumnya. Pada kegiatan ini para Tutor PAUD dibagi menjadi 4 kelompok dan membuat tema masing - masing kelompok. Setelahnya dilakukan presentasi tiap kelompok mengenai pengembangan tema dan puncak tema yang telah dipilih.

Pada pertemuan ke -2 materi pertama yang diberikan yaitu Media untuk Anak Usia Dini. Pada materi ini, dijelaskan bagaimana membuat dan memilih media yang cocok untuk anak usia dini. Selain itu, di materi ini juga memuat karakteristik masing-masing media sesuai dengan kebutuhannya. Materi ini menekankan bahwa media tidak harus membeli barang baru, namun seorang guru harus kreatif memanfaatkan benda-benda sekitar dalam membuat media yang berhubungan dengan tema. Media dalam kegiatan belajar tidak hanya berpaku pada lembar kerja dibuat oleh guru, namun guru juga harus membuat media yang bisa mengembangkan seluruh kemampuan siswa. Setelah itu kelompok yang telah di pertemuan sebelumnya berdiskusi mengenai Media yang sudah dipersiapkan. 


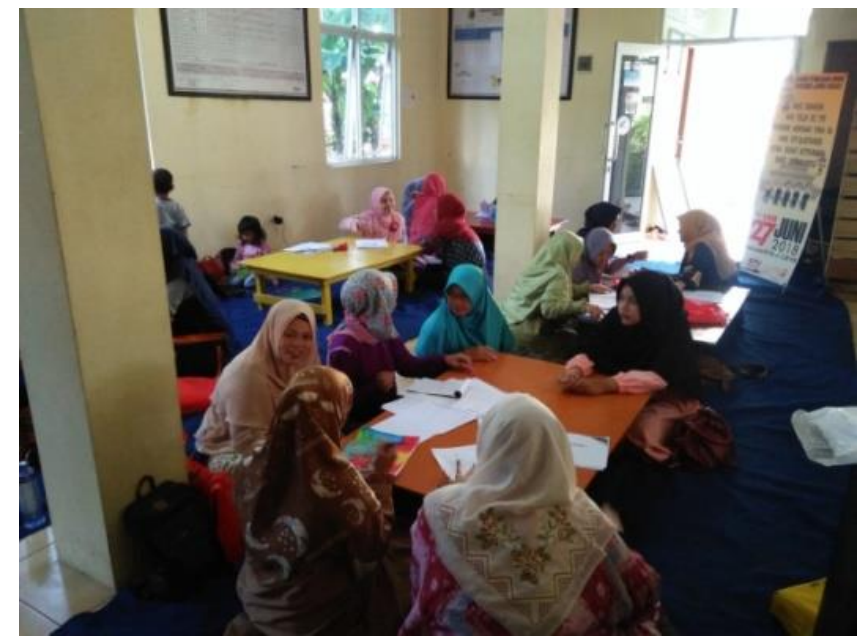

Gambar 3. Para Tutor PAUD sedang Berdiskusi Mengenai Media yang Dipilih

Setelah berdiskusi, tiap kelompok mempraktekkan media tersebut kepada kelompok lainnya. Selanjutnya materi kedua yang diberikan mengenai Panduan Pembuatan RPPH yang lebih rinci juga pembuatan Asesmen dalam menilai pembelajaran siswa. Pada materi ini berisi macammacam asesmen yang dapat digunakan dan perbedaan antara satu jenis asesmen dengan asesmen yang lain. Asesmen yang diberikan meliputi anecdotal record, running record, ceklis, dan rating scale. Asesmen dalam bentuk ceklis paling sering digunakan karena digunakan dalam pembuatan laporan perkembangan anak. Narasumber juga mencontohkan cara penilaian dengan metode ceklis dengan menggunakan indikator perkembangan.

Pada Pertemuan ke -3 materi yang pertama diberikan yaitu mengenai Pendidikan dan Tumbuh Kembang Anak. Pada materi ini dinitikberatkan pada pendidikan karakter yang harus ditanamkan pada Anak Usia Dini. Karakter merupakan sifat asli yang tertanam pada diri seseorang tanpa ingin dipandang hebat oleh orang lain. Selain itu, pentingnya nilai agama juga menjadi poin penting pada materi ini. Nilai-nilai agama mengajarkan tentang adab, akhlak dan karakter. Sehingga karakter seseorang sangat berpengaruh dengan akhlak orang tersebut. Tim juga mengajak para Tutor PAUD untuk merefleksi diri dengan apa yang telah mereka lakukan pada peserta didik di lembaga masing-masing. Diharapkan Tutor PAUD dapat lebih paham mengenai Pendidikan dan Tumbuh Kembang Anak sehingga dapat mencetak anak-anak yang memiliki nilai agama dan memiliki karakter yang baik. Materi selanjutnya mengenai Memulai Jiwa Usaha di Tingkat PAUD. Pada materi ini, Tim mencoba untuk membuka pola pikir peserta bahwa ada hal yang lain bisa dilakukan disamping menjadi guru/tutor PAUD yaitu berwirausaha. Tim memulai dengan menggambar apapun yang terlintas dipikiran peserta saat ingin memulai berwirausaha. Kemudian tiap Tutor 
DOI: https://doi.org/10.21009/sarwahita.152.01

P-ISSN: 0216-7484

E-ISSN: 2597-8926

PAUD diberikan waktu untuk berharga. Tujuannya adalah melihat menggambar sama sepeti yang kebutuhan dari sudut pandang orang lain. dilakukan oleh Tim. Selanjutnya, Kegiatan terkahir yang dilakukan yaitu narasumber meminta peserta untuk mempraktekkan kegiatan sederhana bertanya pada rekan disampingnya yang bisa diterapkan di lembaga masing tentang apa yang saat ini yang sangat - masing.

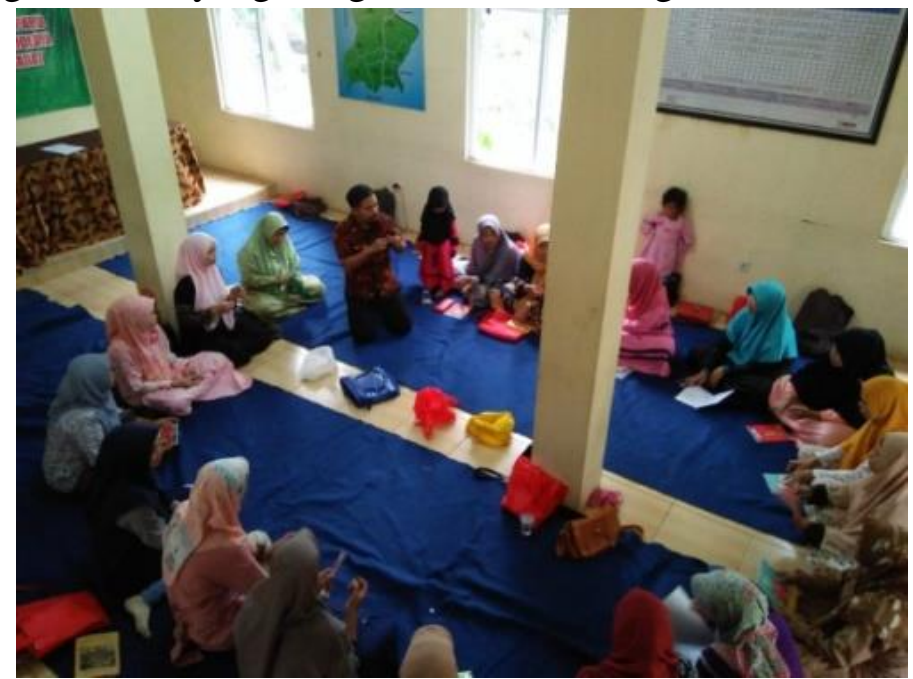

Gambar 4. Salah Satu Kegiatan Sederhana yang Dilakukan Berkaitan Dengan Warna

\section{PENUTUP}

\section{KESIMPULAN}

Peningkatan Profesionalisme Tutor PAUD dalam pengajaran sangat penting, karena keberhasilan proses pembelajaran sangat bergantung pada hal ini. Dari kegiatan pengabdian ini, pengetahuan yang mendukung hal tersebut telah diberikan seperti Pengembangan Kurikulum PAUD Tahun 2013, Konsep PAUD, Pembuatan Perangkat Pembelajaran Berbasis K-13 (RPPH dan Asesmen), Media untuk AUD, Pendidikan dan Tumbuh Kembang Anak serta Memulai Jiwa Usaha di Tingkat PAUD. Respon dari para Tutor PAUD terhadap materi yang telah diberikan tersebut sangat baik sehingga para Tutor PAUD tersebut dapat mengimplementasikan materi - materi tersebut dengan baik dan dapat diterapkan pada lembaga masing masing.

\section{SARAN}

Beberapa saran terkait dengan kegiatan Peningkatan Profesionalisme Guru dan Tutor PAUD Melalui Pelatihan Pembuatan Perangkat Pembelajaran Dalam Upaya Penerapan Kurikulum PAUD Tahun 2013 di Desa Cibitung Tengah Kecamatan Tenjolaya Kabupaten Bogor Propinsi Jawa Barat antara lain :

1. Lokasi kegiatan yang minim air sehingga beberapa peserta kembali pulang hanya untuk buang air kecil/sholat. Ke depannya lebih diperhatikan fasilitas yang ada dilokasi tersebut.

2. Komitmen peserta yang menurun. Beberapa peserta tidak memiliki komitmen yang tinggi sehingga pada beberapa pertemuan tidak datang. Di 
DOI: https://doi.org/10.21009/sarwahita.152.01

P-ISSN: 0216-7484

E-ISSN: 2597-8926

awal kegiatan tim sudah menjelaskan bahwa kegiatan ini menuntut komitmen peserta dari awal hingga selesai kegiatan. Ke depannya perlu diseleksi peserta dan dipilih yang betul-betul memiliki komitmen.

3. Peserta merasa terbantu dengan materi yang diberikan. Mereka berharap kegiatan seperti ini rutin dilakukan agar keilmuan mereka juga terasah dan selalu upgrade.

4. Perluasan jangkauan peserta juga menjadi harapan guru/tutor di luar peserta.

\section{DAFTAR PUSTAKA}

Amini M. 2015. Profil Keterlibatan Orang Tua Dalam Pendidikan Anak Usia TK. Jurnal Ilmiah VISI PPTK PAUDNI - Vol. 10, No.1.

Anjaswari S, Masudah. 2017. Pengaruh Metode Desmonstrasi Terhadap Kemampuan Mengenal Pola Bentuk Geometri Pada Anak Kelompok B TK Yasporbi Jemursari Surabaya. Jurnal PAUD Teratai. Vol. 6 No. 3.

Barret M, Byram M, Lazar I, MompointGaillar P, Philippou S. 2013. Developing Intercultural Competence through Education. Secretariat General, Directorate General II, Directorate Of Democratic Citizenship And Participation.

Gordon AN, Browne KM. 2014. Beginnings and Beyond

Foundations in Early Childhood Education. 9th Edition. America: Wadsworth.

Mirzagitova AL, Akhmetov LG. 2015.

Self - Development of

Pedagogical Competence of

Future Teacher. Canadian Center of Science and Education. International Education Studies; Vol. 8, No. 3.

Purwanti. 2017. Penggunaan Metode

Diskusi Kelompok Dan Pemberian Tugas Dalam Upaya Meningkatkan Prestasi Belajar Ekonomi Materi Pertumbuhan Ekonomi Siswa Kelas Xi Ips 4 Sma Negeri 1 Punggur Semester Ganjil Tahun Pelajaran 2015/2016. Jurnal Pendidikan Ekonomi UM Metro. Vol. 5, No. 1 (2017): $28-36$.

Riyanto A. 2017. Perangkat Pembelajaran Kurikulum 2013 Lengkap dan Terbaru 2017. https://www.amongguru.com/per angkat-pembelajaran-kurikulum2013-lengkap-dan-terbarutahun-2017/ (akses Mei, 2018).

U.S. Supardi. 2012. Arah Pendidikan Di Indonesia Dalam Tataran Kebijakan Dan Implementasi. Jurnal Formatif 2(2): 111 - 121.

Winkel WS. 2010. Psikologi Pengajaran. Yogyakarta: Media Abadi.

Kabupaten

Bogor. http://kecamatantenjolaya.bogor kab.go.id/ (Akses April 2018). 